\title{
Utility of Activated Glassy Carbon and Pencil Graphite Electrodes for Voltammetric Determination of Nalbuphine Hydrochloride in Pharmaceutical and Biological Fluids
}

\author{
Hoda M. Elqudaby, ${ }^{1}$ Hassan A. M. Hendawy, ${ }^{1}$ Eglal R. Souaya, ${ }^{2}$ \\ Gehad G. Mohamed, ${ }^{3}$ and Ghada M. G. Eldin ${ }^{1}$ \\ ${ }^{1}$ National Organization for Drug Control and Research (NODCAR), P.O. Box 29, Cairo, Egypt \\ ${ }^{2}$ Chemistry Department, Faculty of Science, Ain Shams University, Abbasiya 11556, Egypt \\ ${ }^{3}$ Chemistry Department, Faculty of Science, Cairo University, Giza 12613, Egypt \\ Correspondence should be addressed to Ghada M. G. Eldin; ghadagamaleldin@yahoo.com
}

Received 8 October 2015; Revised 25 December 2015; Accepted 27 December 2015

Academic Editor: Shengshui $\mathrm{Hu}$

Copyright ( 2016 Hoda M. Elqudaby et al. This is an open access article distributed under the Creative Commons Attribution License, which permits unrestricted use, distribution, and reproduction in any medium, provided the original work is properly cited.

\begin{abstract}
This work compares voltammetric response of nalbuphine hydrochloride (NP.HCl) at both activated glassy carbon and pencil graphite electrodes. The electrochemical oxidation of the drug was studied using cyclic voltammetry (CV), differential pulse voltammetry (DPV), and square wave voltammetry (SWV) techniques. For analytical purpose a well-resolved irreversible diffusion controlled voltammetric peak was established in Britton-Robinson (B-R) buffer solution of $\mathrm{pH} 6.00$ using pencil graphite electrode (PGE). Using activated glassy carbon electrode (GCE) a well-resolved irreversible diffusion controlled voltammetric peak was obtained at $\mathrm{pH} 7.00$ using the same buffer solution. According to the linear relationship between the peak current and NP.HCl concentration, DPV and SWV methods were developed for their quantitative determination in pharmaceutical and human biological fluids. The linear response was obtained in the range from $1.6 \times 10^{-5}$ to $1.5 \times 10^{-4} \mathrm{~mol} \mathrm{~L}^{-1}$ using PGE and from $12.5 \times 10^{-6}$ to $13.75 \times 10^{-5} \mathrm{~mol} \mathrm{~L}^{-1}$ using a GC electrode, respectively. Precision and accuracy of the developed method were checked by recovery studies.
\end{abstract}

\section{Introduction}

Nalbuphine hydrochloride (NP.HCl) is a phenanthrene derivative. It is an opioid analgesic where it has mixed opioid agonist and antagonist activity. It is used for the relief of moderate to severe pain and as adjunct to anaesthesia. It is structurally related to naloxone and oxymorphone. Pharmacologically, it is quantitatively similar to pentazocine but it is a more potent antagonist at $Л$ opioid acceptors. It is reported to produce no significant cardiovascular effect in patient with ischaemic heart disease. It differs from pure $\pi$ agonists such as morphine in that it is analgesic sedative and has respiratory depressant actions. Actions are subject to a ceiling effect and may not increase proportionately with dose [1]. Nalbuphine has the IUPAC name $(5 \alpha, 6 \alpha)$ 17-(cyclobutyl-methyl)-4,5-expoxymorphinan-3,6,1 4-triol hydrochloride; N-cyclobutylmethyl-14-hydroxydihydro-normorphine (Figure 1) [2].

Very few analytical methods have been established for the determination of NP.HCl in pharmaceuticals, dog, human, and rabbit plasma using high-performance liquid chromatography where either UV or electrochemical detection was used [3-8]. A solid phase extraction procedure was developed for the quantification of NP. $\mathrm{HCl}$ in human plasma with subsequent assay by high-performance liquid chromatography and electrochemical detection [9].

$\mathrm{NP} \cdot \mathrm{HCl}$ was simultaneously determined in human hair by gas chromatography, mass spectrometry [10]. Tranexamic acid derived gold nanoparticles modified glassy carbon electrode was used as a sensor for NP determination where the sensor responded linearly in the range of $0.05-1.25 \mu \mathrm{g}$ $\mathrm{mL}^{-1}$ [11]. NP. $\mathrm{HCl}$ was determined spectrophotometrically 


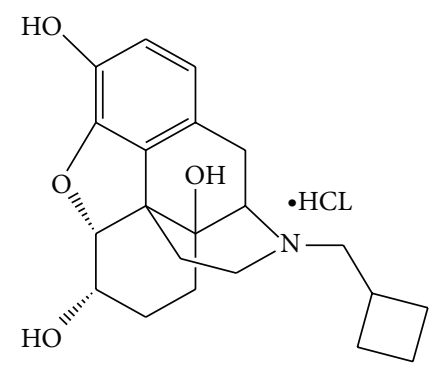

FIgURE 1: Structure of nalbuphine hydrochloride.

using N-bromosuccinimide as an oxidant [12] and stability indicating methods [13].

The advantage of PGE over the existing GCE is its high electrochemical reactivity, commercial availability, good mechanical rigidity, and low cost; the behavior of many pharmaceuticals on GCE was discussed in many of our previous researches [14-16]. Although PGE is relatively new type of carbon electrode, it has been successfully applied to the cathodic and anodic voltammetry by virtue of its high electrochemical reactivity, low technology, and ease of modification [17-22]. In the present work we reported the electrochemical behavior of $\mathrm{NP} \cdot \mathrm{HCl}$ using activated glassy carbon (GCE) and pencil graphite electrode (PGE) in Britton-Robinson buffer of $\mathrm{pH} 6.00$ and 7.00 using pencil graphite electrode (PGE) and activated glassy carbon (GCE) electrode, respectively. Moreover, electroanalytical methods are far less expensive and are more portable than the aforementioned techniques. Specifically, voltammetry is more regularly used in industrial, environmental applications and in the trace drugs detection in their dosage forms and especially in biological samples since it combines excellent sensitivity, selectivity, accuracy, and precision with low cost of instrumentation and maintenance.

Different experimental conditions were studied and then the electrodes were applied successfully for determination of $\mathrm{NP} \cdot \mathrm{HCl}$ in pure, pharmaceutical, and biological fluids. The results obtained can support the use of this suggested voltammetric method in the routine analysis of the cited drug.

\section{Experimental}

2.1. Chemicals and Reagents. Nalbuphine hydrochloride and its pharmaceutical dosage form (Nalufin) were kindly provided by Amoun Company, Cairo, Egypt. All chemicals for preparation of buffers and supporting electrolytes were of reagent grade (Merck or Sigma) which are provided from National Organization for Drug Control and Research (NODCAR). Stock solution of NP.HCl $\left(1.00 \times 10^{-3} \mathrm{~mol} \mathrm{~L}^{-1}\right)$ was prepared in deionized water and kept in the refrigerator. Britton-Robinson buffer $\left(0.04 \mathrm{~mol} \mathrm{~L}^{-1}, \mathrm{pH} 2.00-10.0\right)$ and standard solutions were prepared by serial dilution of the stock solution with selected supporting electrolyte.

2.2. Instrumental and Experimental. Voltammetric measurement was obtained using the electrochemical analyzer computrace system with 797 VA computrace software (1.0) from Metrohm, Switzerland. A three-electrode cell was employed. The working electrodes were a HB rotring tikky hi polymer pencil graphite electrode with a diameter of $0.7 \mathrm{~mm}$ identifiable with S0312690, R505708N and batch number (4006856 505733) and a glassy carbon stationary electrode as a working electrode (mini glassy carbon disk electrode of the active zone: $2.8 \mathrm{~mm}$ for ELCD641/656). Electrical contact with the working electrodes was achieved by soldering a copper wire to the metallic part of the apparatus fixing the pencil; $\mathrm{Ag} / \mathrm{AgCl}\left(3 \mathrm{~mol} \mathrm{~L}^{-1} \mathrm{KCl}\right)$ was used as a reference electrode and platinum wire as a counter electrode. For analytical application, the following parameters were employed: DPV-pulse amplitude $50 \mathrm{mV}$, pulse width $40 \mathrm{~ms}$, and scan rate $100 \mathrm{mVs}^{-1}$; SWV-pulse amplitude $20 \mathrm{mV}$, frequency $50 \mathrm{~Hz}$, potential step $6 \mathrm{mV}$, and electrochemical analyzer made the background subtraction automatically. For CV, the initial and final potentials were variable, depending on the $\mathrm{pH}$ value and the cut-off of the electrolyte. Scan rate measurements in the range of $20-460 \mathrm{mV} \mathrm{s}^{-1}$ were carried out. The $\mathrm{pH}$ measurements were performed using Jenway 3330 Research pH meter, UK. Ultrasonic Cleaner, United Jewelry Tool Supplies, model UTA-60, 6L capacity, Italy, was used: deionized water used throughout the present study was supplied from a Hamilton-Aqua-Metric deionized water system. All the experiments were performed at a temperature of $25^{\circ} \mathrm{C}$.

2.3. Area of the Electrode. In order to determine the active area of graphite pencil and glassy carbon electrodes surface was obtained by applying the cyclic voltammetric method using $1.0 \mathrm{mM} \mathrm{K}_{4} \mathrm{Fe}(\mathrm{CN})_{6}$ at different scan rates. For a reversible process, the following Randles-Sevcik formula was used:

$$
I_{p a}=\left(2.69 \times 10^{5}\right) n^{3 / 2} A_{0} D_{0}^{1 / 2} C_{0}^{*} v^{1 / 2},
$$

where $I_{p a}$ refers to the anodic peak current, $n$ is the number of electrons transferred, $A_{0}$ is the surface area of the electrode, $D_{0}$ is the diffusion coefficient, $v$ is the scan rate, and $C_{0}{ }^{*}$ is the concentration of $\mathrm{K}_{4} \mathrm{Fe}(\mathrm{CN})_{6}$. For $1.0 \mathrm{mM} \mathrm{K}_{4} \mathrm{Fe}(\mathrm{CN})_{6}$ in $0.1 \mathrm{M}$ KCL electrolyte, $n=1, D_{0}=7.6 \times 10^{-6} \mathrm{~cm}^{2} \mathrm{~s}^{-1}$; then from the slope of the plot of $I_{p a}$ versus $v^{1 / 2}$, the electroactive area was calculated. In our experiment electroactive area calculated from Randles-Sevcik equation was found to be 0.269 and $0.097 \mathrm{~cm}^{2}$ for graphite pencil and glassy carbon electrodes, respectively. Electroactive area of PGE has almost doubled active area compared to GCE, so there is a greater response of PGE than GCE on peak current that resulted from $\mathrm{NP} \cdot \mathrm{HCl}$ drug.

2.4. Experimental Procedure. In the electrochemical measurements, pencil graphite electrode was electrochemically pretreated by scanning the potential between 0.02 and $0.30 \mathrm{~V}$ with a scan rate of $20 \mathrm{mV} \mathrm{s}^{-1}$ for 100 cycles in $0.04 \mathrm{~mol} \mathrm{~L}^{-1}$ Britton-Robinson buffer. Voltammetric analyses were performed in $10 \mathrm{~mL}$ of B-R buffer solution $\mathrm{pH} 6.00$ for PGE while they were performed in $20 \mathrm{~mL}$ of $\mathrm{B}-\mathrm{R}$ buffer solution at $\mathrm{pH}$ 7.00 for GCE. Stock solution of the prepared drug solution 


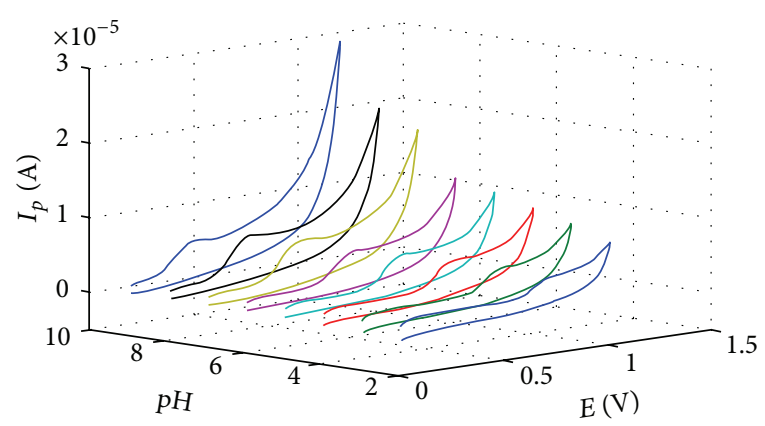

(a)

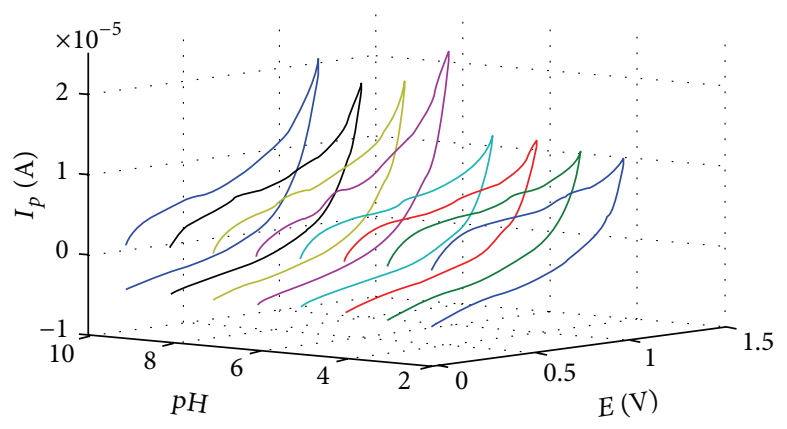

(b)

FIGURE 2: (a) Cyclic voltammogram of different pH at PGE electrode. (b) Cyclic voltammogram of different pH at GCE electrode.

containing 3.939 and $7.878 \mathrm{mg} \mathrm{mL}^{-1}$ of $\mathrm{NP} \cdot \mathrm{HCl}$ for PGE and GCE, respectively, was introduced into the electrolytic cell and after a total of $10 \mathrm{~mm}$ of pencil graphite was immersed into the supporting electrolyte. The cyclic voltammograms were recorded at a scan rate $60 \mathrm{mV} \mathrm{s}^{-1}$. The calibration curves of NP.HCl using DPV and SWV were established by plotting the peak current $I_{p}(\mu \mathrm{A})$ against drug concentration $\left(\mathrm{mol} \mathrm{L}^{-1}\right)$. The analytical parameters such as ruggedness, precision, relative standard deviations, limit of detection, and limit of quantification were calculated to check the accuracy and precision of the proposed method.

2.4.1. Analysis of Pharmaceutical Dosage Form. The PGE and GCE were applied for the determination of nalufin ampoule with a specified content of $\mathrm{NP} \cdot \mathrm{HCl}$ of $20 \mathrm{mg} \mathrm{mL}^{-1}$. The procedure for sample was $1 \mathrm{~mL}$ portion of nalufin ampoule, was pipetted into a $25 \mathrm{~mL}$ calibrated flask, and was diluted up to the mark with deionized water. The amount of NP. HCl per ampoule was calculated using the linear regression equation obtained from the calibration curve of pure $\mathrm{NP} \cdot \mathrm{HCl}$.

2.4.2. Application to Human Urine. Direct application to human urine and without any sample pretreatment like precipitation was carried out. Urine was supplied from healthy volunteers, allowed to settle for about 30 minutes, and then used for the experiments. A drug solution of $\mathrm{NP} \cdot \mathrm{HCl}$ dissolved in deionized water to achieve a final concentration of $20 \mathrm{mg} \mathrm{mL}^{-1}$ appropriate volumes of this sample was transferred into the voltammetric cell and diluted up to the volume with Britton-Robinson buffer at $\mathrm{pH} 6.00$ and 7.00 for PGE and GCE, respectively, and subsequently analyzed according to the recommendation in the general analytical procedure. An aliquot of human urine sample was collected and analyzed as a sample.

\section{Results and Discussion}

3.1. Electrooxidation of NP.HCl. The oxidation behavior of $\mathrm{NP} \cdot \mathrm{HCl}$ was studied over $\mathrm{pH}$ range of $2.00-10.0$ in various supporting electrolytes. The cyclic voltammogram of NP. HCl in B-R buffer at pH 6.00 or pH 7.00 in case of PGE and GCE, respectively, was shown in Figure 2.
The electrochemical behavior of the NP. $\mathrm{HCl}$ drug at the selected $\mathrm{pH}$ endued one main irreversible anodic peak at 472 and $413 \mathrm{mV}$ for both PGE and GCE, respectively. On the reverse scan no corresponding reduction peak was observed, so the behavior of NP.HCl drug undergoes irreversible oxidation process.

3.2. Effect of $p H$. To study the effectiveness of $\mathrm{pH}$ on electrodes reaction and select the suitable $\mathrm{pH}$ for oxidation of $\mathrm{NP} \cdot \mathrm{HCl}$ drug using PGE and GCE, the irreversible oxidation reaction of $1.0 \times 10^{-3} \mathrm{~mol} \mathrm{~L}^{-1} \mathrm{NP} \cdot \mathrm{HCl}$ drug was studied over the $\mathrm{pH}$ range 2.00 to 10.0 in $\mathrm{B}-\mathrm{R}$ buffer solution by cyclic voltammetry. The solution $\mathrm{pH}$ influenced the peak current and peak potential considerably with the increase in $\mathrm{pH}$ of the solution where peak potential was shifted to less positive values and obeys the following equations:

$$
\begin{aligned}
& E_{p}(\mathrm{mV})=899.7-62.45 \mathrm{pH} \\
& \qquad\left(r^{2}=0.9993\right) \text { for PGE, } \\
& E_{p}(\mathrm{mV})=800.18-51.53 \mathrm{pH} \\
& \qquad\left(r^{2}=0.9991\right) \text { for GCE. }
\end{aligned}
$$

The slope of this equation is found to be 62.45 and $51.53 \mathrm{mV} / \mathrm{pH}$ for PGE and GCE, respectively. This closeness of the slope to the expected theoretical value [23] of $59 \mathrm{mV} / \mathrm{pH}$ suggests that the number of the electrons transferred during oxidation process is equal to that of the hydrogen ions taking part in the electrode reaction.

The proposed mechanism of the electrooxidation of $\mathrm{NP} \cdot \mathrm{HCl}$ can be given as in Scheme 1.

From the plot of $I_{p}$ versus pH (Figure 3), it is clear that the intensity of the peak current was increased to a high value at $\mathrm{pH} 6.00$ and $\mathrm{pH} 7.00$ for PGE and GCE, respectively. Then the peak intensity decreases because the best result with respect to sensitivity accompanied with sharper response was obtained with these $\mathrm{pH}$ values. Therefore, $\mathrm{pH} 6.00$ and $\mathrm{pH}$ 7.00 were selected for further experimental studies.

3.3. Effect of Scan Rate. The effect of scan rate on the electrooxidation of NP.HCl was examined by cyclic voltammetry (Figure 4). The effect of the square root of the scan rate on 

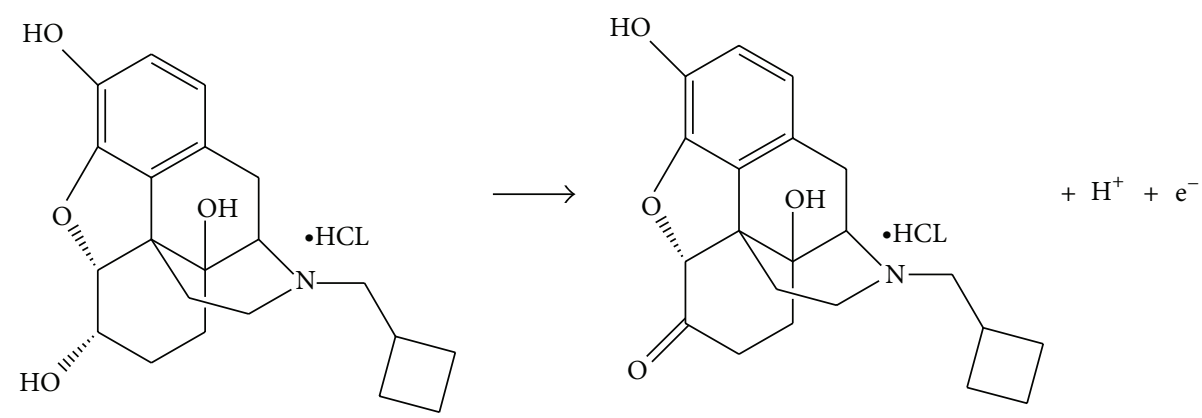

SCHEME 1: Mechanism of the electrooxidation of NP·HCl drug.

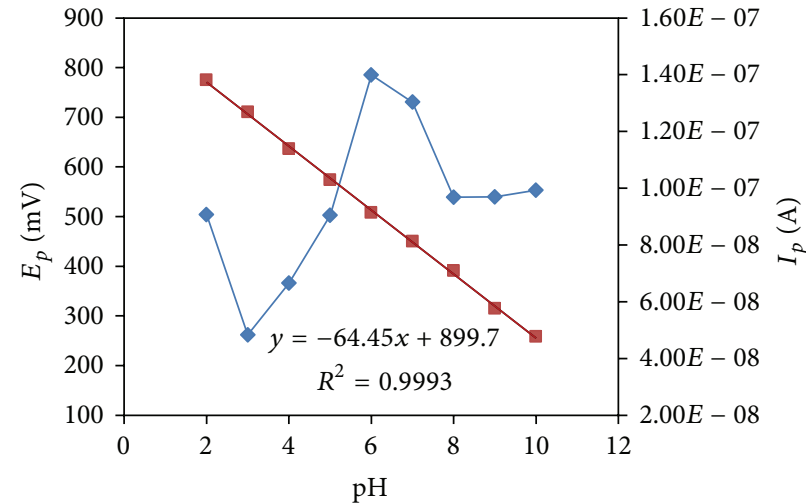

(a)

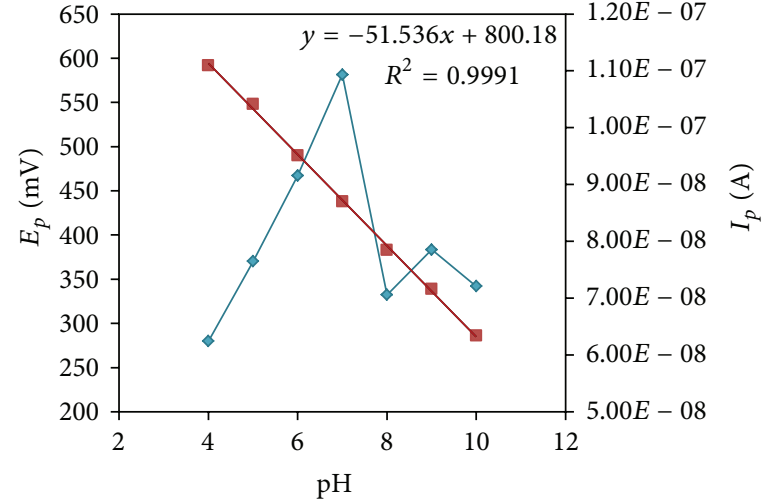

(b)

FIGURE 3: (a) The effect of $\mathrm{pH}$ on the current peak and potential of $\mathrm{NP} \cdot \mathrm{HCl}$ at PGE electrode. (b) The effect of $\mathrm{pH}$ on the current peak and potential of $\mathrm{NP} \cdot \mathrm{HCl}$ at GCE electrode.

the anodic peak current showed a linear relationship between square root of the scan rate and anodic peak current as shown in Figure 4 which was of exemplary diffusion controlled currents [24]. The equation can be expressed as follows:

$$
\begin{array}{ll}
I_{p}(\mu \mathrm{A})=4 v_{2}^{1}+0.2 & \left(r^{2}=0.9996\right) \text { for PGE} \\
I_{p}(\mu \mathrm{A})=3 v_{2}^{1}+0.3 & \left(r^{2}=0.9993\right) \text { for GCE. }
\end{array}
$$

Also there is a linear relationship that was observed between $\log I_{p}$ and $\log v$ (Figure 4) which follows the equation:

$$
\begin{aligned}
\log I_{p}(\mu \mathrm{A})= & 0.419 \log v \\
& +1.563\left(r^{2}=0.9996\right) \text { for PGE, } \\
\log I_{p}(\mu \mathrm{A})= & 0.576 \log v \\
& +1.609\left(r^{2}=0.9997\right) \text { for GCE, }
\end{aligned}
$$

which made it clear that the slope values of 0.419 and 0.576 for PGE and GCE, respectively, were comparable with theoretically expected value of 0.5 for a diffusion controlled process which confirms that the electrooxidation of $\mathrm{NP} \cdot \mathrm{HCl}$ was diffusion controlled using both PGE and GCE electrodes.

From Figure 4, it is noticed that any increase in the scan rate causes shift in the peak potential to a positive value and a linear relationship was observed in the range of 20 to $240 \mathrm{mV} \mathrm{s}^{-1}$ scan rate. The equation can be expressed as

$$
\begin{array}{ll}
E_{p}=52.25 \log v+570.81 & \left(r^{2}=0.9948\right) \text { for PGE, } \\
E_{p}=70.28 \log v+468.32 & \left(r^{2}=0.9923\right) \text { for GCE. }
\end{array}
$$

In order to calculate the number of electron transfers during oxidation for an irreversible electrode process, according to Laviron [25], $E_{p}$ is defined by the following equation:

$$
\begin{aligned}
E_{p}= & E^{o}+\left(\frac{2.303 R T}{\alpha n F}\right) \log \left(\frac{R K K^{o}}{\alpha n F}\right) \\
& +\left(\frac{2.303 R T}{\alpha n F}\right) \log v,
\end{aligned}
$$

where $\alpha$ is the transfer coefficient, $K^{o}$ is the standard heterogeneous rate constant of the reaction, $n$ is number of electrons transferred, $v$ is the scan rate, and $E^{o}$ is the thermal standard redox potential. Thus, the value of $\alpha n$ can be easily calculated from the slope of $E_{p}$ versus $\log v$ plot. In this system, the slope was 0.05225 and 0.07028 for PGE and GCE, respectively. Taking $T=298 \mathrm{~K}, R=8.314 \mathrm{~J} \mathrm{~K}^{-1} \mathrm{~mol}^{-1}$, and $F=96480 \mathrm{C} \mathrm{mol}^{-1}$, the $\alpha n$ value was calculated to be 1.132 


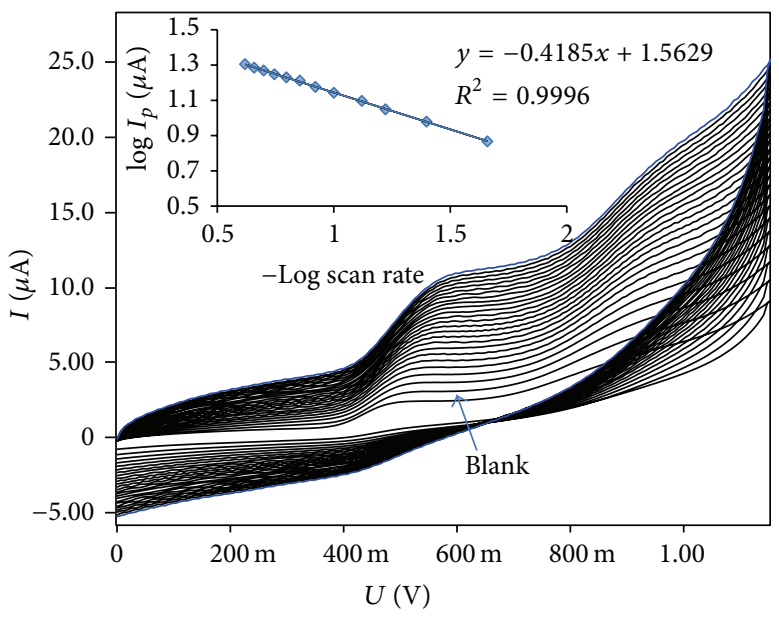

(a)

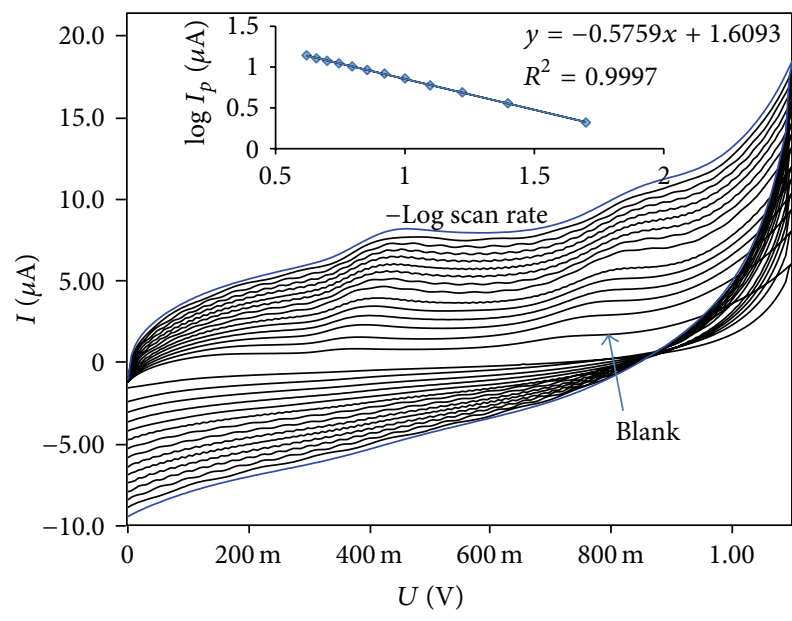

(b)

Figure 4: (a) The effect of scan rates $\left(\mathrm{mV} \mathrm{s}^{-1}\right)$ on the peak current $I_{p}(\mu \mathrm{A})$ of NP.HCl drug at PGE electrode at $\mathrm{pH}=6$. (b) The effect of scan rate $\left(\mathrm{mV} \mathrm{s}^{-1}\right)$ on the peak current $I_{p}(\mu \mathrm{A})$ of NP.HCl drug at GCE electrode at $\mathrm{pH}=7$.

TABLE 1: Analytical parameters of nalbuphine $\mathrm{HCl}$ drug at PGE by using DPV and SWV methods.

\begin{tabular}{|c|c|c|c|}
\hline \multirow{2}{*}{ Parameters } & \multirow{2}{*}{ Differential pulse voltammetry (DPV) } & \multicolumn{2}{|c|}{ Square wave voltammetry (SWV) } \\
\hline & & Peak 1 & Peak 2 \\
\hline $\mathrm{pH}$ & 6 & 6 & 6 \\
\hline Concentration range $\left(\mathrm{mol} \mathrm{L}^{-1}\right)$ & $1.6 \times 10^{-5}-1.5 \times 10^{-4}$ & $1.6 \times 10^{-5}-1.5 \times 10^{-4}$ & $3.33 \times 10^{-5}-1.5 \times 10^{-4}$ \\
\hline SD & $2.21 \times 10^{-8}$ & $1.13 \times 10^{-7}$ & $2.56 \times 10^{-8}$ \\
\hline RSD \% & 0.678 & 0.655 & 1.036 \\
\hline Slope of regression line (a) & 0.0115 & 0.0095 & 0.0115 \\
\hline Intercept of regression line $(b)$ & $4.47 \times 10^{-5}$ & $6.79 \times 10^{-7}$ & $4.47 \times 10^{-7}$ \\
\hline Correlation coefficient $(r)$ & 0.9995 & 0.9995 & 0.9993 \\
\hline SEE & $1.21 \times 10^{-8}$ & $1.03 \times 10^{-8}$ & $1.2 \times 10^{-8}$ \\
\hline $\mathrm{LOD}\left(\mathrm{mol} \mathrm{L}^{-1}\right)$ & $6.38 \times 10^{-6}$ & $3.91 \times 10^{-5}$ & $1.13 \times 10^{-5}$ \\
\hline $\operatorname{LOQ}\left(\mathrm{mol} \mathrm{L}^{-1}\right)$ & $1.93 \times 10^{-5}$ & $1.18 \times 10^{-4}$ & $3.43 \times 10^{-5}$ \\
\hline
\end{tabular}

and 0.842 for PGE and GCE, respectively, according to Bard and Faulkner [26], where $\alpha$ can be given as

$$
\alpha=\frac{47.7}{E_{p}-E_{p / 2}} \mathrm{MV},
$$

where $E_{p / 2}$ was the potential when the current was at half the peak value. From this, the value of $\alpha$ was calculated to be 0.7 and 0.8 for PGE and GCE, respectively. Then, the number of electrons $(n)$ transferred in the electrooxidation of NP. HCl was calculated to be 1.2 and 1.0 for PGE and GCE, respectively. The value of $K^{o}$ can be determined from the intercept of the previous plot if the value of $E^{o}$ is known. The value of $E^{o}$ in (6) can be obtained from the intercept of $E_{p}$ versus $v$ curve by extrapolating to the vertical axis at $v=0$ [27]. In the system under study the intercept for $E_{p}$ versus $\log v$ plot was 0.4873 and 0.3639 for GCE and PGE, respectively, and $E^{o}$ was found to be 363 and 488 for PGE and GCE, respectively $[26,28]$.

3.4. Analytical Applications. In order to develop a voltammetric methodology for determination of the drug, we selected the DPV and SWV methods, since the peaks were sharper and better defined at lower concentration of $\mathrm{NP} \cdot \mathrm{HCl}$; then those obtained by cyclic and linear sweep voltammetry with a lower background current lead to improvement in resolution. The precision of the method was evaluated by repeating three experiments on the same day and in the same standard condition to maintain the repeatability of the proposed method. For these studies $5.00 \times 10^{-3} \mathrm{~mol} \mathrm{~L}^{-1}$ of $\mathrm{NP} \cdot \mathrm{HCl}$ solution was used. The results were given as shown in Tables 1 and 2.

In order to provide DPV and SWV quantitative procedure, the dependence of the peak current on the drug concentration was investigated. Linear calibration curves were obtained for NP concentration in the range from $1.6 \times$ $10^{-5}$ to $1.5 \times 10^{-4}$ and $3.33 \times 10^{-5}$ to $1.5 \times 10^{-4} \mathrm{~mol} \mathrm{~L}^{-1}$ for the first and the second peaks, respectively, in case of PGE so $\mathrm{NP} \cdot \mathrm{HCl}$ has two electroactive sites which are characterized by the high electron density where oxidation is most likely to occur and from $12.5 \times 10^{-6}$ to $13.75 \times 10^{-5} \mathrm{~mol} \mathrm{~L}^{-1}$ in case of GCE (Figure 5). The characterization of these graphs was shown in Tables 1 and 2. The limit of detection (LOD) and 
TABLE 2: Analytical parameters of nalbuphine $\mathrm{HCl}$ drug at GCE by using DPV and SWV methods.

\begin{tabular}{lccc}
\hline \multirow{2}{*}{ Parameters } & Differential pulse voltammetry (DPV) & \multicolumn{2}{c}{ Square wave voltammetry (SWV) } \\
& & Peak 1 & 7 \\
pH & 7 & $2.5 \times 10^{-6}-2.75 \times 10^{-5}$ & $1.0 \times 10^{-5}-2.75 \times 10^{-5}$ \\
Concentration range $\left(\mathrm{mol} \mathrm{L}^{-1}\right)$ & $1.25 \times 10^{-5}-1.38 \times 10^{-4}$ & $1.17 \times 10^{-8}$ & $2.27 \times 10^{-8}$ \\
SD & $4.26 \times 10^{-9}$ & 0.5652 & 0.6053 \\
RSD \% & 0.5595 & 0.0389 & 0.0189 \\
Slope of regression line (a) & 0.0033 & $7.49 \times 10^{-7}$ & $4.16 \times 10^{-8}$ \\
Intercept of regression line (b) & $3.43 \times 10^{-7}$ & 0.9997 & 0.9995 \\
Correlation coefficient $(r)$ & 0.9993 & $3.73 \times 10^{-8}$ & $3.23 \times 10^{-8}$ \\
SEE & $2.43 \times 10^{-9}$ & $9.96 \times 10^{-7}$ & $3.94 \times 10^{-6}$ \\
LOD (mol L & & $\left.3.02 \times 10^{-6}\right)$ & $1.19 \times 10^{-5}$ \\
LOQ $\left(\mathrm{mol} \mathrm{L}^{-1}\right)$ & $4.26 \times 10^{-6}$ & $1.29 \times 10^{-5}$ & \\
\hline
\end{tabular}

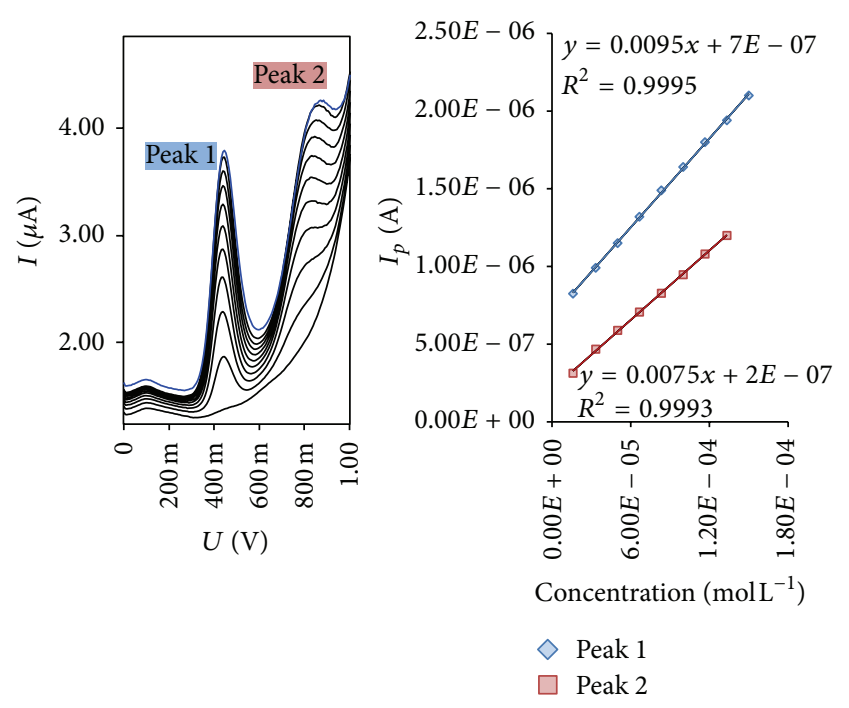

(a)

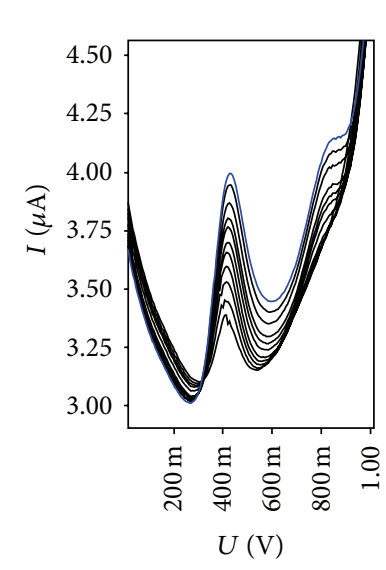

(b)

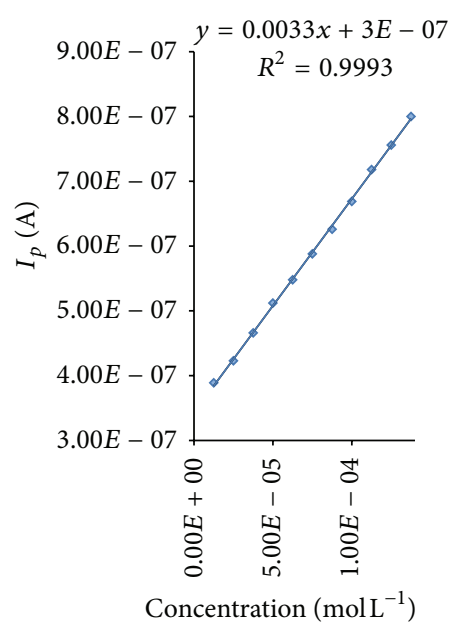

Figure 5: (a) Calibration graph of NP.HCl drug by using DPV method at PGE electrode, (1) $1.6 \times 10^{-5} \mathrm{~mol} \mathrm{~L}^{-1},(2) 3.33 \times 10^{-5} \mathrm{~mol} \mathrm{~L}^{-1},(3) 5.00 \times$ $10^{-5} \mathrm{~mol} \mathrm{~L}^{-1}$, (4) $6.66 \times 10^{-5} \mathrm{~mol} \mathrm{~L}^{-1}$, (5) $8.33 \times 10^{-5} \mathrm{~mol} \mathrm{~L}^{-1}$, (6) $1.00 \times 10^{-4} \mathrm{~mol} \mathrm{~L}^{-1}$, (7) $1.17 \times 10^{-4} \mathrm{~mol} \mathrm{~L}^{-1}$, (8) $1.33 \times 10^{-4} \mathrm{~mol} \mathrm{~L}^{-1}$, and (9) $1.6 \times$ $10^{-4} \mathrm{~mol} \mathrm{~L}^{-1}$. (b) Calibration graph of NP.HCl drug by using DPV method at GCE electrode, (1) $1.25 \times 10^{-5} \mathrm{~mol} \mathrm{~L}^{-1},(2) 2.50 \times 10^{-5} \mathrm{~mol} \mathrm{~L}-1$, (3) $3.75 \times 10^{-5} \mathrm{~mol} \mathrm{~L}^{-1},(4) 5.00 \times 10^{-5} \mathrm{~mol} \mathrm{~L}^{-1},(5) 6.25 \times 10^{-5} \mathrm{~mol} \mathrm{~L}^{-1},(6) 7.50 \times 10^{-5} \mathrm{~mol} \mathrm{~L}^{-1},(7) 8.75 \times 10^{-5} \mathrm{~mol} \mathrm{~L}^{-1},(8) 1.00 \times 10^{-4} \mathrm{~mol} \mathrm{~L}^{-1}$, (9) $1.13 \times 10^{-4} \mathrm{~mol} \mathrm{~L}^{-1},(10) 1.25 \times 10^{-4} \mathrm{~mol} \mathrm{~L}^{-1}$, and (11) $1.38 \times 10^{-4} \mathrm{~mol} \mathrm{~L}^{-1}$.

the limit of quantification (LOQ) were also shown in Tables 1 and 2.

LOD and LOQ were calculated on the peak current using the following equations:

$$
\begin{aligned}
& \mathrm{LOD}=3 \frac{s}{m}, \\
& \mathrm{LOQ}=10 \frac{\mathrm{s}}{\mathrm{m}},
\end{aligned}
$$

where $s$ is standard deviation of the peak current five runs and $m$ is the slope of the calibration curve [29].

Applicability of the PGE and GCE was investigated for the determination of $\mathrm{NP} \cdot \mathrm{HCl}$ in a pharmaceutical ampule Nalufin $\left(20 \mathrm{mg} \mathrm{mL}^{-1}\right)$. Differential pulse voltammograms were obtained by adding appropriate standard solution to diluted solution under the optimized conditions described earlier. The results of determination of $\mathrm{NP} \cdot \mathrm{HCl}$ in ampule dosage forms were shown in Table 3. A recovery of 100.2 and $99.98 \%$ with relative standard deviation of 0.8 and $0.94 \%$ using PGE and GCE was obtained, respectively.

The resulting mean values of $\mathrm{NP} \cdot \mathrm{HCl}$ content in pharmaceutical formulation for PGE and GCE showed good agreement with the declared values of $20 \mathrm{mg} / \mathrm{NP}$ ampule. These results indicated that PGE has adequate precision and accuracy for the determination of NP. HCl.

3.5. Detection of NP.HCl in Spiked Human Urine. The applicability of the proposed technique to human urine was investigated. The calibration curve was obtained for spiked samples and represented graphically in Figure 6. The obtained regression equation and related validation parameter are shown in Table 4 . To determine $\mathrm{NP} \cdot \mathrm{HCl}$ drug in spiked urine samples neither time consuming extraction and evaporation steps nor sample pretreatment was required. The proposed 
TABLE 3: Statistical parameters of pharmaceutical dosage form assay of the investigated drug by the proposed SWV method at PGE and GCE and reported method.

\begin{tabular}{|c|c|c|c|c|c|c|}
\hline Electrode & Drug & $\begin{array}{c}{[\mathrm{NP} \cdot \mathrm{HCl}] \text { taken }} \\
\mu \mathrm{g} \mathrm{mL}^{-1}\end{array}$ & $\begin{array}{l}\text { Proposed method } \\
\text { Mean } \pm \text { SD }(n=5)\end{array}$ & $\begin{array}{c}\text { Official method } \\
\text { Mean } \pm \text { SD }(n=5)\end{array}$ & $F$-test & $t$-test \\
\hline \multirow{3}{*}{ PGE } & \multirow{3}{*}{ Nalufin $\left(20 \mathrm{mg} \mathrm{mL}^{-1}\right)$} & 10 & $100.2 \pm 0.80$ & $99.41 \pm 2.00$ & 1.45 & 1.56 \\
\hline & & 20 & $99.98 \pm 1.11$ & $100.2 \pm 1.32$ & 1.70 & 1.81 \\
\hline & & 30 & $100.5 \pm 0.65$ & $99.74 \pm 1.00$ & 1.85 & 1.96 \\
\hline \multirow{3}{*}{ GCE } & \multirow{3}{*}{ Nalufin $\left(20 \mathrm{mg} \mathrm{mL}^{-1}\right)$} & 20 & $100.7 \pm 1.10$ & $99.41 \pm 2.00$ & 2.57 & 1.25 \\
\hline & & 40 & $100.90 \pm 0.88$ & $100.2 \pm 1.32$ & 2.78 & 1.45 \\
\hline & & 60 & $99.98 \pm 0.94$ & $100.74 \pm 1.00$ & 2.85 & 1.23 \\
\hline
\end{tabular}

Tabulated $t$-value at $95 \%$ confidence limit $=2.77, n=5$, degree of freedom $=4$.

Tabulated $F$-value at $95 \%$ confidence limit $=6.39, n=5$.

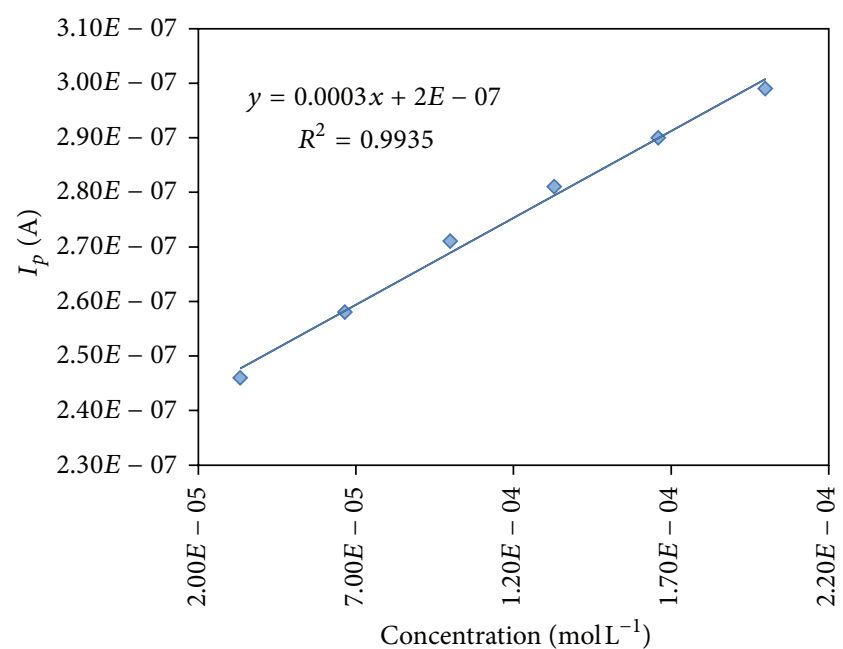

(a)

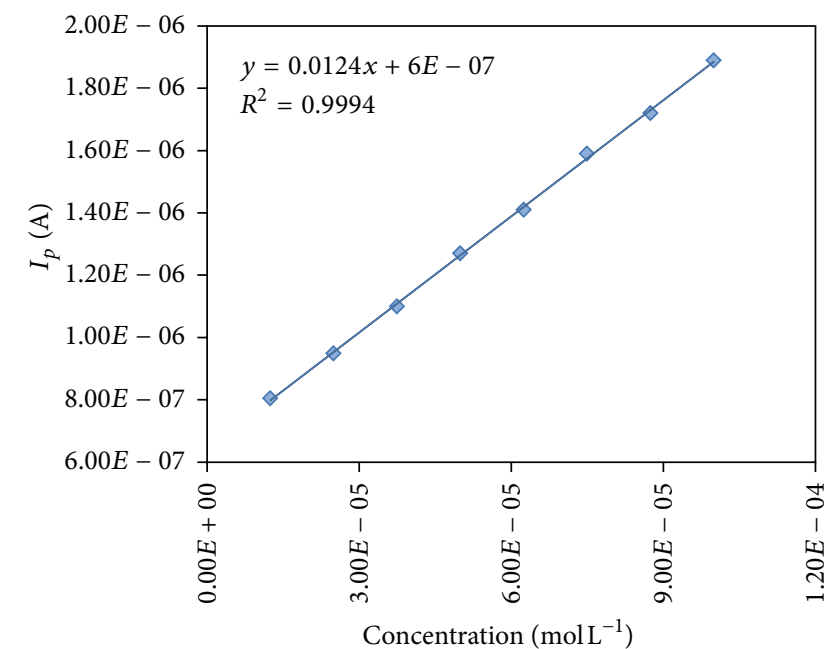

(b)

FIGURE 6: (a) Calibration graphs of NP.HCl in spiked urine samples by using SWV method at PGE electrode, $(1) 3.33 \times 10^{-5} \mathrm{~mol} \mathrm{~L}^{-1},(2) 6.66 \times$ $10^{-5} \mathrm{~mol} \mathrm{~L}^{-1}$, (3) $1.00 \times 10^{-4} \mathrm{~mol} \mathrm{~L}^{-1}$, (4) $1.33 \times 10^{-4} \mathrm{~mol} \mathrm{~L}^{-1}$, (5) $1.66 \times 10^{-4} \mathrm{~mol} \mathrm{~L}^{-1}$, and (6) $2.00 \times 10^{-4} \mathrm{~mol} \mathrm{~L}^{-1}$. (b) Calibration graphs of NP. HCl in spiked urine samples by using SWV method at GCE electrode, (1) $1.25 \times 10^{-5} \mathrm{~mol} \mathrm{~L}^{-1},(2) 2.50 \times 10^{-5} \mathrm{~mol} \mathrm{~L}^{-1},(3) 3.75 \times 10^{-5} \mathrm{~mol} \mathrm{~L}^{-1}$, (4) $5.00 \times 10^{-5} \mathrm{~mol} \mathrm{~L}^{-1}$, (5) $6.25 \times 10^{-5} \mathrm{~mol} \mathrm{~L}^{-1}$, (6) $7.50 \times 10^{-5} \mathrm{~mol} \mathrm{~L}^{-1}$, (7) $8.75 \times 10^{-5} \mathrm{~mol} \mathrm{~L}^{-1}$, and (8) $1.00 \times 10^{-4} \mathrm{~mol} \mathrm{~L}^{-1}$.

TABLE 4: Determination of NP. HCl in urine samples using PGE and GCE electrodes.

\begin{tabular}{|c|c|c|c|c|}
\hline \multicolumn{2}{|c|}{ Sample Urine spiked $(\mu \mathrm{M})$} & \multirow{2}{*}{$\begin{array}{c}\text { Detected }(\mu \mathrm{M}) \\
\text { PGE }\end{array}$} & \multirow[t]{2}{*}{ Recovery \% } & \multirow[t]{2}{*}{ RSD \% } \\
\hline & & & & \\
\hline 1 & 3.33 & 3.31 & 99.39 & 1.13 \\
\hline 2 & 6.66 & 6.70 & 100.60 & 0.72 \\
\hline 3 & 10.0 & 9.97 & 99.7 & 0.43 \\
\hline 4 & 13.3 & 13.29 & 99.92 & 0.68 \\
\hline 5 & 16.6 & 16.51 & 99.46 & 1.24 \\
\hline \multicolumn{5}{|c|}{ GCE } \\
\hline 1 & 12.5 & 12.39 & 99.12 & 0.942 \\
\hline 2 & 25.0 & 24.71 & 98.84 & 1.22 \\
\hline 3 & 37.5 & 37.1 & 98.93 & 1.07 \\
\hline 4 & 50.0 & 50.23 & 100.46 & 0.88 \\
\hline 5 & 62.5 & 62.12 & 99.39 & 0.954 \\
\hline
\end{tabular}

method gave reproducible results and was easy to perform and sensitive enough for the determination of NP. $\mathrm{HCl}$ drug in human urine sample. The stability of urine sample kept in a refrigerator $\left( \pm 4^{\circ} \mathrm{C}\right)$ was tested by performing five consecutive analyses of the samples over a period of approximately $5 \mathrm{~h}$. There were no significant differences in the peak currents and potentials between the first and the last measurements.

3.6. Precision (Repeatability and Reproducibility). The intraand interday precision were evaluated by assaying freshly prepared solutions in triplicate on the same day and on three different days, respectively, using the proposed method. The repeatability (intraday) and reproducibility (interday) of the results obtained by means of the proposed SWV procedure were examined and the results indicated high accuracy and precision of the proposed procedure and proved to be suitable for quality control of NP. $\mathrm{HCl}$ (Table 5).

\section{Conclusion}

In the presented study, an accurate, simple, and sensitive cyclic, DPV, and SWV voltammetric determination of $\mathrm{NP} \cdot \mathrm{HCl}$ drug was employed in pure and dosage forms using 
TABLE 5: Inter- and intradays regression parameters using SWV method for determination of NP.HCl drug.

\begin{tabular}{|c|c|c|c|c|c|c|}
\hline Parameter & & PGE & & & GCE & \\
\hline Concentration $\mu \mathrm{g} \mathrm{mL}^{-1}$ & 5.00 & 7.00 & 10.00 & 12.00 & 17.00 & 20.00 \\
\hline Intraday* & $100.5 \pm 1.32$ & $100.2 \pm 1.11$ & $99.8 \pm 1.14$ & $99.0 \pm 1.20$ & $99.7 \pm 0.86$ & $98.5 \pm 1.24$ \\
\hline Interday $^{*}$ & $101.3 \pm 0.84$ & $99.7 \pm 0.86$ & $98.9 \pm 1.28$ & $99.5 \pm 1.57$ & $98.3 \pm 0.87$ & $99.8 \pm 0.30$ \\
\hline
\end{tabular}

${ }^{*}$ Each result is the average of three separate measurements.

the most popular and simpler working electrodes named graphite pencil electrode (PGE) and activated glassy carbon electrode (GCE) [30] where the electrooxidative behavior of the cited drug was studied. It showed one well-defined irreversible anodic peak. Different parameters were tested to optimize the best condition for determination and the analytical procedure was fully validated regarding linearity precision, accuracy, reproducibility, sensitivity, and selectivity. The method developed was also compared with the reference one [31] and was proved to be a satisfactory alternative for the fast, simple, and clean quantitative determination of NP. $\mathrm{HCl}$.

According to LOD and LOQ electrochemical characterization of both electrodes towards NP. $\mathrm{HCl}$ oxidation, it is clear that PGE has the highest electrocatalytic activity followed by a divided GCE. This work will be continued in order to apply this method as recommended routine analysis of the drug under study.

\section{Conflict of Interests}

The authors declare that there is no conflict of interests regarding the publication of this paper.

\section{Acknowledgment}

The authors would like to express their gratitude to Department of Analytical Chemistry at Faculty of Science, Ain Shams University, Cairo University, and National Organization for Drug Control and Research (NODCAR, Egypt) for providing instruments and the means necessary to accomplish this work.

\section{References}

[1] A. Brayfield, Martindale: "The Complete Drug Reference" Drug Monographs Volume A, Pharmaceutical Press, Gurnee, Ill, USA, 38th edition, 2012.

[2] M. J. O'Neil, Ed., The Merck Index, RSC Publishing, 15th edition, 2013.

[3] L.-H. Pao, C.-H. Hsiong, O. Y.-P. Hu, and S.-T. Ho, "Highperformance liquid chromatographic method for the simultaneous determination of nalbuphine and its prodrug, sebacoyl dinalbuphine ester, in dog plasma and application to pharmacokinetic studies in dogs," Journal of Chromatography B: Biomedical Sciences and Applications, vol. 746, no. 2, pp. 241247, 2000.

[4] S.-H. Ho, J.-J. Wang, O. Y.-P. Hu, P.-S. Chiang, and S.C. Lee, "Determination of nalbuphine by high-performance liquid chromatography with ultraviolet detection: application to human and rabbit pharmacokinetic studies," Journal of
Chromatography B: Biomedical Sciences and Applications, vol. 678, no. 2, pp. 289-296, 1996.

[5] F. de Cazanove, J.-M. Kinowski, M. Audran, A. Rochette, and F. Bressolle, "Determination of nalbuphine in human plasma by high-performance liquid chromatography with electrochemical detection. Application to a pharmacokinetic study," Journal of Chromatography B: Biomedical Applications, vol. 690, no. 1-2, pp. 203-210, 1997.

[6] D. Groenendaal, M. C. M. Blom-Roosemalen, M. Danhof, and E. C. M. De Lange, "High-performance liquid chromatography of nalbuphine, butorphanol and morphine in blood and brain microdialysate samples: application to pharmacokinetic/pharmacodynamic studies in rats," Journal of Chromatography $B$, vol. 822, no. 1-2, pp. 230-237, 2005.

[7] L. M. Dubé, N. Beaudoin, M. Lalande, and I. J. McGilveray, "Determination of nalbuphine by high-performance liquid chromatography with electrochemical detection: application to clinical samples from post-operative patients," Journal of Chromatography B: Biomedical Sciences and Applications, vol. 427, pp. 113-120, 1988.

[8] P. Kintz, A. Tracqui, and P. Mangin, "Determination of nalbuphine using high-performance liquid chromatography coupled to photodiode-array detection and gas chromatography coupled to mass spectrometry," Journal of Chromatography B: Biomedical Sciences and Applications, vol. 579, no. 1, pp. 172-176, 1992.

[9] E. Nicolle, S. Veitl, C. Guimier, and G. Bessard, "Modified method of nalbuphine determination in plasma: validation and application to pharmacokinetics of the rectal route," Journal of Chromatography B: Biomedical Applications, vol. 690, no. 1-2, pp. 89-97, 1997.

[10] J. Young Kim, M. Kyo In, K. Jung Paeng, and B. Chul Chung, "Simultaneous determination of nalbuphine and opiates in human hair by gas chromatography-mass spectrometry," Chromatographia, vol. 59, no. 3-4, pp. 219-226, 2004.

[11] T. Shaikh, A. Nafady, F. N. Talpur et al., "Tranexamic acid derived gold nanoparticles modified glassy carbon electrode as sensitive sensor for determination of nalbuphine," Sensors and Actuators B: Chemical, vol. 211, pp. 359-369, 2015.

[12] A. M. El-Didamony, M. Z. Saad, and N. O. Saleem, "Spectrophotometric determination of some analgesic drugs in pharmaceutical formulations using N-bromosuccinimide as an oxidant," Journal of the Association of Arab Universities for Basic and Applied Sciences, vol. 17, pp. 43-50, 2015.

[13] M. M. Fouad, S. A. Abdel Razaq, Z. A. Elsayed, and L. A. Hussin, "Stability indicating methods for determination of nalbuphinehydrochloride," British Journal of Pharmaceutical Research, vol. 3, no. 2, pp. 259-272, 2013.

[14] H. M. Elqudaby, G. G. Mohamed, F. A. Ali, and S. M. Eid, "Validated voltammetric method for the determination of some antiprotozoa drugs based on the reduction at an activated glassy carbon electrode," Arabian Journal of Chemistry, vol. 6, no. 3, pp. 327-333, 2013. 
[15] H. M. Elqudaby, G. G. Mohamed, and G. M. G. El Din, "Electrochemical behaviour of trimebutine at activated glassy carbon electrode and its direct determination in urine and pharmaceutics by square wave and differential pulse voltammetry," International Journal of Electrochemical Science, vol. 9, pp. 856869, 2014.

[16] H. M. Elqudaby, H. A. M. Hendawy, and M. A. Zayed, "Microdetermination of entecavir drug in its pharmaceuticals forms and in biological fluids using anodic voltammetry," World Journal of Pharmaceutical Research, vol. 7, pp. 1115-1120, 2014.

[17] A. Levent, Y. Yardim, and Z. Senturk, "Voltammetric behavior of nicotine at pencil graphite electrode and its enhancement determination in the presence of anionic surfactant," Electrochimica Acta, vol. 55, no. 1, pp. 190-195, 2009.

[18] W. Gao, J. Song, and N. Wu, "Voltammetric behavior and square-wave voltammetric determination of trepibutone at a pencil graphite electrode," Journal of Electroanalytical Chemistry, vol. 576, no. 1, pp. 1-7, 2005.

[19] D. Demetriades, A. Economou, and A. Voulgaropoulos, "A study of pencil-lead bismuth-film electrodes for the determination of trace metals by anodic stripping voltammetry," Analytica Chimica Acta, vol. 519, no. 2, pp. 167-172, 2004.

[20] H. Karadeniz, B. Gulmez, F. Sahinci et al., "Disposable electrochemical biosensor for the detection of the interaction between DNA and lycorine based on guanine and adenine signals," Journal of Pharmaceutical and Biomedical Analysis, vol. 33, no. 2, pp. 295-302, 2003.

[21] A. M. Bond, P. J. Mahon, J. Schiewe, and V. Vicente-Beckett, "An inexpensive and renewable pencil electrode for use in fieldbased stripping voltammetry," Analytical Chemistry Acta, vol. 345, no. 1-3, pp. 67-74, 1997.

[22] E. Dede, Ö. Sağlam, and Y. Dilgin, "Sensitive voltammetric determination of niclosamide at a disposable pencil graphite electrode," Electrochimica Acta, vol. 127, pp. 20-26, 2014.

[23] I. Martin, F. C. Gritiani, L. S. Canaes, F. A. de Souza Campos Junior, L. M. da Silva Cruz, and S. Rath, "Determination of parabens in shampoo using high performance liquid chromatography with amperometric detection on a boron-doped diamond electrode," Talanta, vol. 85, no. 1, pp. 1-7, 2011.

[24] D. K. Gosser, Cyclic Voltammetry: Simulation and Analysis of Chemical Mechanism, VCH, New York, NY, USA, 1993.

[25] E. Laviron, "General expression of the linear potential sweep voltammogram in the case of diffusionless electrochemical systems," Journal of Electroanalytical Chemistry, vol. 101, no. 1, pp. 19-28, 1979.

[26] A. J. Bard and L. R. Faulkner, Electrochemical Methods Fundamentals and Applications, Wiley, 2nd edition, 2004.

[27] Y. Wu, X. Ji, and S. Hu, "Studies on electrochemical oxidation of azithromycin and its interaction with bovine serum albumin," Bioelectrochemistry, vol. 64, no. 1, pp. 91-97, 2004.

[28] M. P. Miranda, R. Del Rio, M. A. Del Valle, M. Faundez, and F. Armijo, "Use of fluorine-doped tin oxide electrodes for lipoic acid determination in dietary supplements," Journal of Electroanalytical Chemistry, vol. 668, pp. 1-6, 2012.

[29] E. Swartz and I. S. Krull, Analytical Method Development and Validation, Marcel Dekker, New York, NY, USA, 1997.

[30] J. Wang, Analytical Electrochemistry, John Wiley \& Sons, 2nd edition, 1948.

[31] Edition Cantorverlag, Aulendorf, Germany, ECV, p. 1035, 2002. 

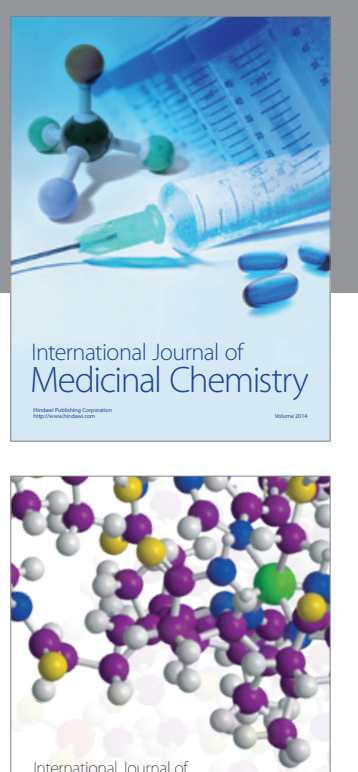

Carbohydrate Chemistry

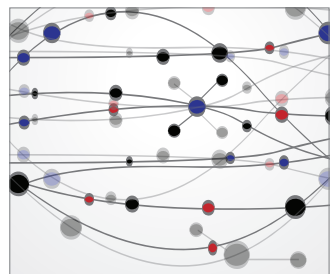

The Scientific World Journal
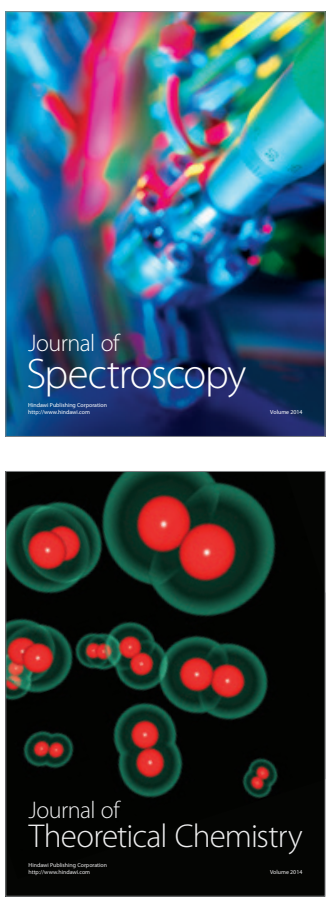
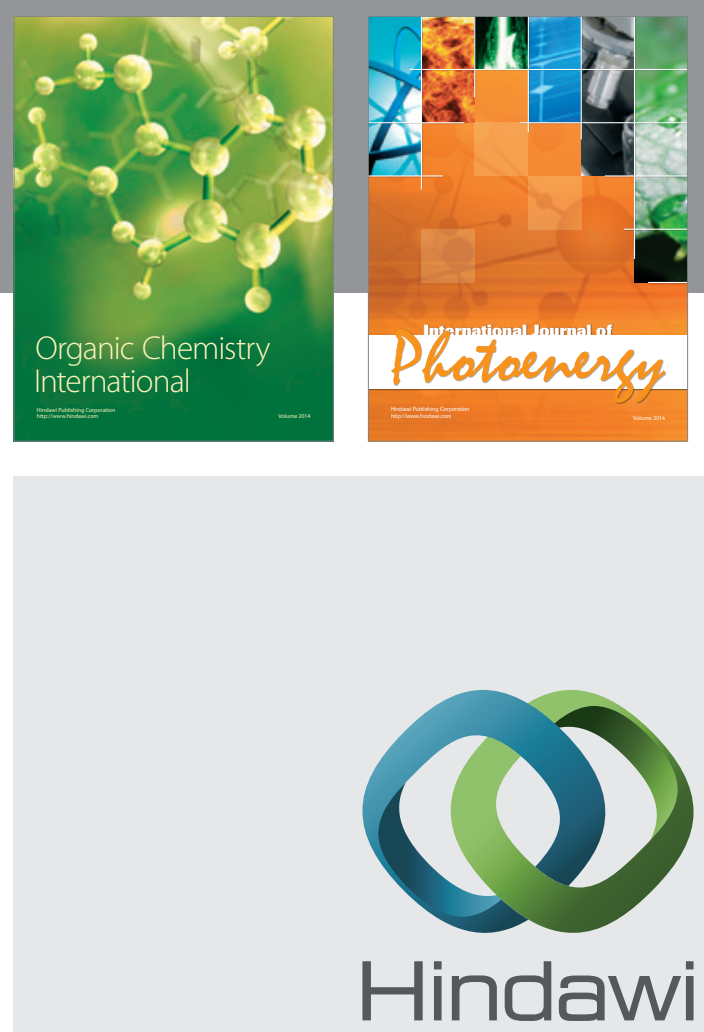

Submit your manuscripts at

http://www.hindawi.com

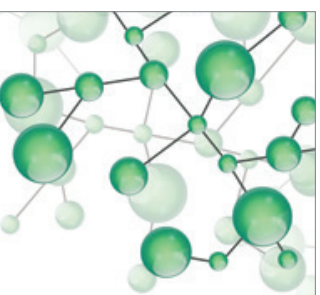

International Journal of

Inorganic Chemistry

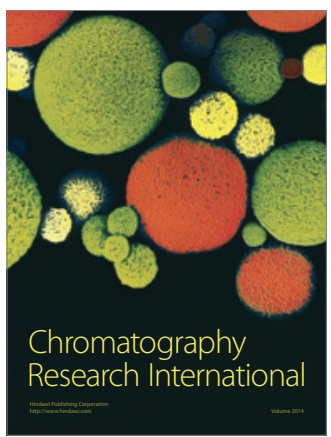

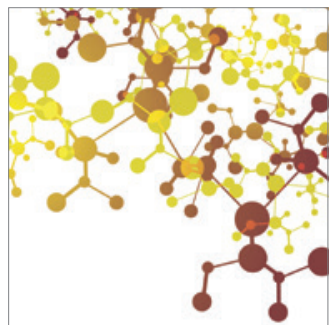

Applied Chemistry
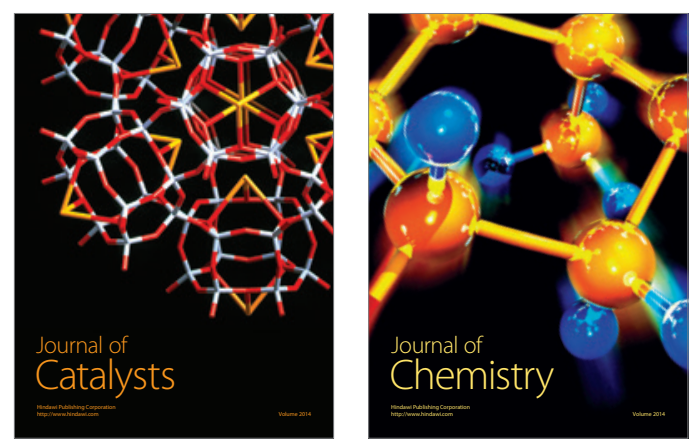
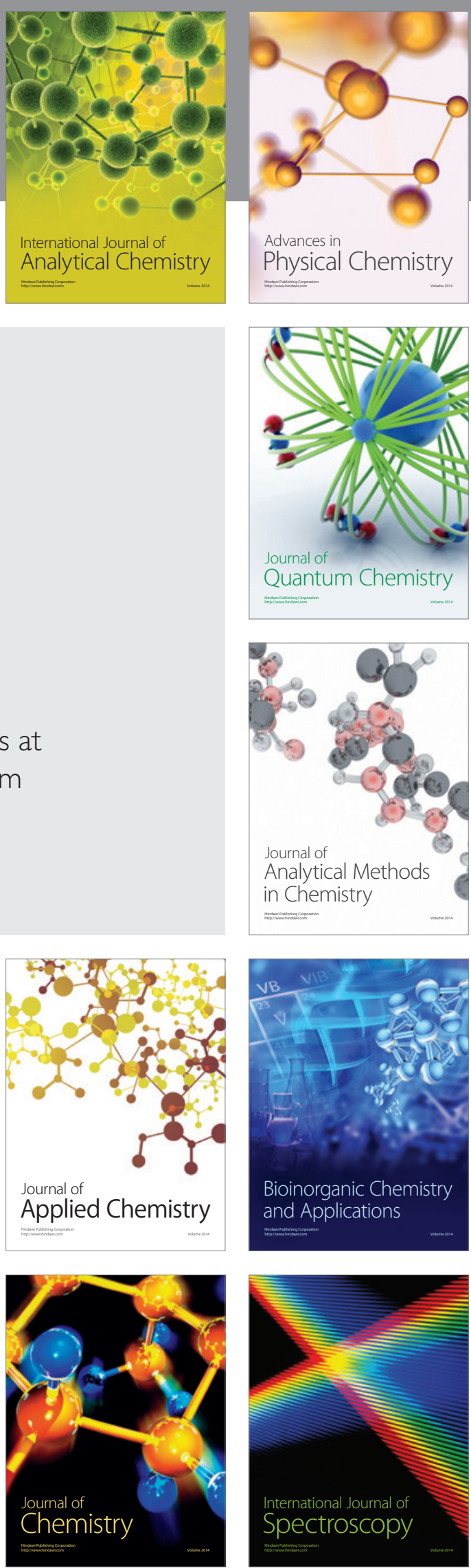